\title{
Jugular vein distensibility predicts fluid responsiveness in septic patients
}

\author{
Fabio Guarracino ${ }^{1 *}$, Baldassarre Ferro ${ }^{1}$, Francesco Forfori ${ }^{2}$, Pietro Bertini ${ }^{1}$, Luana Magliacano ${ }^{2}$ and Michael R Pinsky ${ }^{3}$
}

\begin{abstract}
Introduction: The purpose of the study was to verify the efficacy of using internal jugular vein (IJV) size and distensibility as a reliable index of fluid responsiveness in mechanically ventilated patients with sepsis.

Methods: Hemodynamic data of mechanically ventilated patients with sepsis were collected through a radial arterial indwelling catheter connected to continuous hemodynamic monitoring system (Most Care ${ }^{\oplus}$, Vytech Health, Padova, Italy), including cardiac index $(\mathrm{Cl})\left(\mathrm{L} / \mathrm{min} / \mathrm{M}^{2}\right)$, heart rate (beats/min), mean arterial pressure (MAP) $(\mathrm{mmHg})$, central venous pressure (CVP) $(\mathrm{mmHg})$ and arterial pulse pressure variation (PPV), coupled with ultrasound evaluation of IJV distensibility (\%), defined as a ratio of the difference between IJV maximal antero-posterior diameter during inspiration and minimum expiratory diameter to minimum expiratory diameter $\times 100$. Patients were retrospectively divided into two groups; fluid responders (R), if $\mathrm{Cl}$ increase of more than or equal to 15\% after a 7 $\mathrm{ml} / \mathrm{kg}$ crystalloid infusion, and non-responders (NR) if $\mathrm{Cl}$ increased more than $15 \%$. We compared differences in measured variables between $\mathrm{R}$ and NR groups and calculated receiver-operator-characteristic (ROC) curves of optimal IJV distensibility and PPV sensitivity and specificity to predicting R. We also calculated a combined inferior vena cava distensibility-PPV ROC curve to predict R.
\end{abstract}

Results: We enrolled 50 patients, of these, 30 were R. Responders presented higher IJV distensibility and PPV before fluid challenge than NR $(P<0.05)$. An IJV distensibility more than $18 \%$ prior to volume challenge had an $80 \%$ sensitivity and $85 \%$ specificity to predict R. Pairwise comparison between IJV distensibility and PPV ROC curves revealed similar ROC area under the curve results. Interestingly, combining IJV distensibility more than $9.7 \%$ and PPV more than $12 \%$ predicted fluid responsiveness with a sensitivity of $100 \%$ and specificity of $95 \%$.

Conclusion: IJV distensibility is an accurate, easily acquired non-invasive parameter of fluid responsiveness in mechanically ventilated septic patients with performance similar to PPV. The combined use of IJV distensibility with left-sided indexes of fluid responsiveness improves their predictive value.

\section{Introduction}

Increasing cardiac output by volume expansion is a cornerstone treatment of critically ill patients with sepsis presumed to have tissue hypoperfusion. Fluid resuscitation is performed because it is assumed that the heart is operating of the steep ascending portion of the Frank-Starling curve (preload-responsive). However, fluid resuscitation in the non-preload-responsive patient may be deleterious if it promotes cor pulmonale, pulmonary edema, or peripheral

\footnotetext{
* Correspondence: fabiodoc64@hotmail.com

'Department of Anesthesia and Critical Care Medicine, Cardiothoracic Anesthesia and Intensive Care Medicine, Azienda Ospedaliero Universitaria Pisana, Via Paradisa, 256123 Pisa, Italy

Full list of author information is available at the end of the article
}

edema [1]. It is therefore useful to have reliable predictors of volume responsiveness.

Several studies have emphasized the reduced clinical value of static hemodynamic parameters, such as central venous pressure (CVP) and pulmonary artery occluding pressure, as compared with dynamic parameters in predicting fluid responsiveness $[2,3]$. Such dynamic indicators include positive-pressure ventilation-induced changes in left ventricular stroke volume and arterial pulse pressure (PP) [4]. Similarly, ultrasound evaluation of respiratory variations of both superior and inferior vena cava diameter accurately reflects volume responsiveness $[5,6]$. Specifically, both the superior vena cava (SVC) collapsibility index, calculated as the ratio of the difference in maximal diameter at expiration and the minimal diameter at inspiration 
to maximal diameter with insufflation, and the inferior vena cava (IVC) distensibility index, calculated as the difference in maximal diameter at inflation and minimal diameter at expiration predict volume responsiveness [6]. IVC imaging can be problematic in the obese and those with ascites, and SVC imaging, though more accurate requires transesophageal echocardiography, limiting its application.

Many clinical examples, from tricuspid regurgitation to heart failure, from right heart failure to both hypoand hypervolemia illustrate that any time pressure and volume change within the intrathoracic systemic venous compartment a change also occurs in extrathoracic veins, such as in the intra-abdominal IVC or extrathoracic internal jugular vein (IJV) [7-10]. Based on this linkage of intrathoracic venous pressure and volume to extrathoracic venous pressure we hypothesized that right heart functional status relative to its volume responsiveness should be reflected by changes in IJV pressures as assessed by IJV diameter changes.

Since IJV imaging does not require transesophageal echocardiography and is technically easier to perform than IVC visualization, we tested the hypothesis that respiratory changes in IJV diameter in mechanically ventilated patients would also predict fluid responsiveness.

\section{Materials and methods}

After approval from the ethical committee for human biomedical of Azienda Ospedaliero Universitaria Pisana and the University of Pittsburgh, a prospective study was established elaborating hemodynamic data obtained from patients presenting sepsis, according to the definition of, and treated following the indications of the Surviving Sepsis Campaign [11]. Patients with history of any cardiac disease, evidence of jugular vein thrombosis or atrial fibrillation were excluded. Informed consent was obtained from all patients.

All enrolled patients older than 18 years were mechanically ventilated in mandatory minute ventilation (MMV) modality in supine position with the head elevated to $30^{\circ}$, and with ventilatory parameters adjusted to maintain Pplat $<30 \mathrm{cmH}_{2} \mathrm{O}$ (median $20 \mathrm{cmH}_{2} \mathrm{O}$, IQR 18 to 22), $\mathrm{PCO}_{2}<40 \mathrm{mmHg}$ (respiratory rate median 16 breaths per minute, IQR 12 to 17$), \mathrm{SaO}_{2}>96 \%$, with a tidal volume of 6 to $8 \mathrm{ml} / \mathrm{kg}$, positive end-expiratory pressure (PEEP) of $6 \mathrm{cmH}_{2} \mathrm{O}$ (median $6 \mathrm{cmH}_{2} \mathrm{O}$, IQR 5 to 7$)$ and inspired oxygen fraction $\left(\mathrm{FiO}_{2}\right)$ of 0.4 .

We analyzed a series of measured hemodynamic variables from an indwelling radial arterial catheter in septic patients. These data included cardiac index (CI) (L/ $\min / \mathrm{M}^{2}$ ), heart rate (beats/minute), mean arterial pressure (MAP) (mmHg), CVP ( $\mathrm{mmHg}$ ) and pulse pressure variation (PPV) using the the Most Care (Vytech Health, Padova, Italy) continuous hemodynamic monitoring system based on the pressure recording analytical method (PRAM) algorithm [12]. PPV is defined as the ratio of the maximum difference in PP observed over three respiratory cycles and the average of these two PPs as follows:

$$
\left(P P_{\text {max }}-P P_{\text {min }}\right) /\left(\left(P P_{\text {max }}+P P_{\text {min }}\right) / 2\right) .
$$

A PPV $>13 \%$ was presumed to identify those patients who would increase their cardiac output by $>15 \%$ in response to a $500-\mathrm{ml}$ colloid fluid bolus, as previously validated [4].

We simultaneously collected the hemodynamic data and an ultrasound (US) examination of the IJV by the same operator. The ultrasound examination was performed with a $12-\mathrm{MHz}$ linear transducer (Esaote, Milan, Italy) and ultrasound system (MyLab ${ }^{\text {Tx }} 50$ XVision). The IJV was visualized with two-dimensional echo at the level of the cricoid cartilage and recognized by compression, color Doppler and pulse wave Doppler sampling. As the patient position can influence IJV, all measurements were performed in the semi-recumbent position (head elevated $30^{\circ}$ ).

The antero-posterior (AP) IJV diameter was measured using M-mode during a respiratory cycle. In order to avoid changes in vein diameter unrelated to respiratory variation, gentle pressure by the US probe was used to collapse the IJV in order to distinguish it from the carotid artery, then the pressure was relieved to the US probe-skin interface and attention was given to avoid influence of probe compression on IJV dimensions [13] during the US examination. Moreover, in order to avoid interference of probeto-vein angle, the JV evaluation was performed by positioning the probe perpendicular to the skin and oriented orthogonally to the JV short-axis diameter (Figure 1). The IJV distensibility index (\%) was calculated as the ratio of the difference in the maximal IJV AP diameter during inspiration and minimum IJV expiratory diameter to the minimum IJV expiratory diameter $\times 100$.

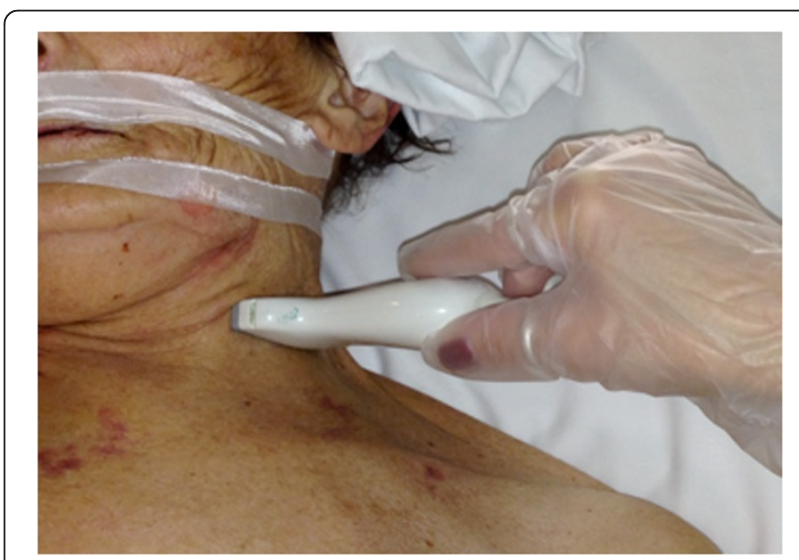

Figure 1 Ultrasound probe position for internal jugular vein detection at the cricoid cartilage level. The patient is in the supine position at $30^{\circ}$ with head rotation of $30^{\circ}$. 
Table 1 Hemodynamic parameters measured in responders and non responders

\begin{tabular}{|c|c|c|c|}
\hline Parameters & Responders & Non responders & $P$-value \\
\hline \multirow{2}{*}{$\begin{array}{l}\text { Heart rate, time }(T) 0, \\
\text { beats/minute }\end{array}$} & 6 & 82 & 0.2 \\
\hline & 75 to 100 & 73 to 90 & \\
\hline \multirow[t]{2}{*}{ Heart rate, $\mathrm{T} 1$, beats/minute } & 80 & 81 & 0.8 \\
\hline & 72 to 86 & 71 to 88 & \\
\hline \multirow{2}{*}{$\begin{array}{l}\text { Heart rate change } \mathrm{T} 0 \text { to } \\
\mathrm{T} 1 \text {, beats/minute }\end{array}$} & -6 & -1 & 0.001 \\
\hline & -11 to 2 & -3.5 to 1.5 & \\
\hline \multirow{2}{*}{$\begin{array}{l}\text { Systolic pressure, } \\
\text { T0, } \mathrm{mmHg} / \mathrm{ml}\end{array}$} & 124 & 112 & 0.9 \\
\hline & 110 to 135 & 101.5 to 142.5 & \\
\hline \multirow{2}{*}{$\begin{array}{l}\text { Systolic pressure, } \\
\mathrm{T} 1, \mathrm{mmHg} / \mathrm{ml}\end{array}$} & 137 & 125 & 0.39 \\
\hline & 123 to 151 & 116.5 to 150 & \\
\hline \multirow{2}{*}{$\begin{array}{l}\text { Systolic pressure change } \\
\text { T0 to } \mathrm{T} 1, \mathrm{mmHg} / \mathrm{ml}\end{array}$} & 15 & 12 & 0.06 \\
\hline & 11 to 20 & 2.5 to 16 & \\
\hline \multirow[t]{2}{*}{ Cardiac index, T0, L/minute } & 2.2 & 2.45 & 0.18 \\
\hline & 2.1 to 2,4 & 2.1 to 2.8 & \\
\hline \multirow[t]{2}{*}{ Cardiac index, $T 1, \mathrm{~L} /$ minute } & 2.95 & 2.8 & 0.02 \\
\hline & 2.7 to 3.3 & 2.27 to 3 & \\
\hline \multirow{2}{*}{$\begin{array}{l}\text { Cardiac index change, } \\
\text { T0 to T1, \% }\end{array}$} & 36.1 & 5.25 & $<0.0001$ \\
\hline & 27.2 to 42 & 3.65 to 12 & \\
\hline \multirow{2}{*}{$\begin{array}{l}\text { Central venous pressure, } \\
\mathrm{TO}, \mathrm{mmHg}\end{array}$} & 9.8 & 10 & 0.15 \\
\hline & 7.8 to 11.9 & 11 to 12.5 & \\
\hline \multirow{2}{*}{$\begin{array}{l}\text { Central venous pressure, } \\
\mathrm{T} 1, \mathrm{mmHg}\end{array}$} & 13 & 13.5 & 0.49 \\
\hline & 10.5 to 13.9 & 12 to 15 & \\
\hline \multirow{2}{*}{$\begin{array}{l}\text { Central venous pressure } \\
\text { change, } \mathrm{T0} \text { to } \mathrm{T} 1, \mathrm{mmHg}\end{array}$} & 3 & 2 & 0.01 \\
\hline & 2 to 3 & 1 to 2 & \\
\hline \multirow{2}{*}{$\begin{array}{l}\text { Pulse pressure } \\
\text { variation, T0, \% }\end{array}$} & 22.5 & 12.2 & $<0.0001$ \\
\hline & 18 to 32 & 18 to 32 & \\
\hline \multirow{2}{*}{$\begin{array}{l}\text { Pulse pressure } \\
\text { variation, } \mathrm{T1}, \%\end{array}$} & 9.5 & 7.9 & 0.20 \\
\hline & 7 to 16.5 & 5.65 to 13.5 & \\
\hline \multirow{2}{*}{$\begin{array}{l}\text { Pulse pressure variation } \\
\text { change, T0 to } \mathrm{T} 1, \%\end{array}$} & -14 & -3.4 & $<0.0001$ \\
\hline & -16 to -7 & -5.2 to 2.5 & \\
\hline \multirow[t]{2}{*}{ IJV distensibility T0, \% } & 24.15 & 9.8 & $<0.0001$ \\
\hline & 20 to 29 & 7.6 to 13.8 & \\
\hline \multirow[t]{2}{*}{ IJV distensibility, T1, \% } & 8.9 & 12.2 & 0.07 \\
\hline & 4.9 to 13.4 & 9.1 to 13.8 & \\
\hline $\begin{array}{l}\text { IJV distensibility change } \\
\text { T0 to T1, \% }\end{array}$ & -12.5 & 1.1 & $<0.0001$ \\
\hline
\end{tabular}

Table 1 Hemodynamic parameters measured in responders and non responders (Continued)

\begin{tabular}{|c|c|c|c|}
\hline & -19.4 to 10.9 & -1.5 to 3.1 & \\
\hline \multirow{2}{*}{$\begin{array}{l}\text { Norepinephrine, } \\
\text { T0, mcg kg }{ }^{-1} \min ^{-1}\end{array}$} & 0.1 & 0.1 & 0.5 \\
\hline & 0.05 to 0.2 & 0.04 to 0.2 & \\
\hline \multirow{2}{*}{$\begin{array}{l}\text { Norepinephrine, } \\
\text { T1, mcg kg }{ }^{-1} \min ^{-1}\end{array}$} & 0.09 & 0.14 & 0.1 \\
\hline & 0.05 to 0.2 & 0.0 to 0.3 & \\
\hline
\end{tabular}

All ultrasound measurements were performed before $\left(\mathrm{T}_{0}\right)$ and immediately after $\left(\mathrm{T}_{1}\right)$ 30-minute volume expansion with a $7-\mathrm{ml} / \mathrm{kg}$ crystalloid infusion. IJV distensibility was evaluated offline by an investigator blinded to the results of the fluid challenge on CI. Two consecutive measures of IJV diameters were obtained before and after fluid challenge on the first 15 patients to evaluate intraobserver variability.

Vasoactive drug infusion rates and ventilation settings were not changed during this 30-minute observation interval. Patients were defined as fluid responders ( $R$ ) if an increase in $\mathrm{CI}(\Delta \mathrm{CI}) \geq 15 \%$ was obtained after volume expansion, and non-responders (NR) if $\Delta \mathrm{CI}$ was $<15 \%$.

\section{Statistical analysis}

Data were expressed as median and IQR. The nonparametric Mann-Whitney and Wilcoxon test was used. The concordance correlation coefficient was obtained to assess intraobserver variability. Receiver operator characteristic (ROC) curves were built to obtain maximal sensitivity and specificity of PPV and IJV distensibility to predict fluid responsiveness (that is, $\Delta \mathrm{CI} \geq 15 \%$ ). Furthermore, we analyzed the sensitivity and specificity of the combination of PPV and IJV distensibility in predicting fluid responsiveness. We classified patients in cases $\mathrm{R}$ or NR according to two criteria $(\times 1, \times 2)$ using thresholds c1 and c2. In order to compute the ROC curve, we then quantified the number of observed true positive and true negative when we classified patients to be cases if $y 1<=$ $\mathrm{c} 1$ and $\mathrm{y} 2<=\mathrm{c} 2$, for a variety of $\mathrm{c} 1$ and $\mathrm{c} 2$ (that is, all combinations of y1 and y2). Significance was defined by a $P$-value $<0.05$. Comparison between ROC curves was made using the De Long method.

\section{Results}

From October 2012 to December 2013, we enrolled fifty septic patients (32 males and 18 females; 67, 56 to 76, median age and IQR age). None of them suffered from acute respiratory distress syndrome (ARDS) at the time of enrollment. Hemodynamic and US evaluation data are reported in Table 1 . Thirty patients were R and 20 were NR. 
Consecutive measurements obtained in 15 patients showed substantial agreement with a concordance correlation coefficient of 0.98 (CI 0.96, 0.99) before fluid challenge and $0.98(0.96,0.99)$ after volume replacement.

Basal heart rate (HR) was not different between the $R$ and NR groups either before or after the volume challenge, though HR tended to decrease with volume challenge in $\mathrm{R}$. Responders displayed an increase of systolic $(P=0.01)$ and mean $(P=0.05)$ arterial pressure, and a decrease in $\operatorname{HR}(P=0.0001)$, with no change in diastolic arterial pressure. No significant changes in arterial pressure and no variation in HR were observed in NR group. $\mathrm{CI}$ increased in both groups $(\mathrm{R}, P=0.0001$; NR, $P=$ 0.001). Despite a significant increase in CVP after fluid challenge in all patients $(12,10$ to $13 \mathrm{mmHg}$ to 13 , IQR11, 7 to $15 \mathrm{mmHg}, P=0.0001)$, there was no difference in CVP between $\mathrm{R}$ and NR before $(P=0.15)$ or after volume expansion $(P=0.49)$. $\mathrm{R}$ displayed a higher variation of CVP than NR $(P=0.01)$.

Responders presented higher IJV distensibility before volume expansion (Figure 2$)$ than NR $(P=0.0001)$ (Figure 3$)$. This difference was lost following volume challenge $(P=$ 0.07). Responders had a significant reduction of IJV distensibility from baseline to post-volume expansion $(P=$ $0.0001)$ not seen in NR $(P=0.26)$. Responders showed a higher initial PPV than NR $(P=0.0001)$. This difference was lost following volume challenge $(P=0.2)$. Both $\mathrm{R}$ and NR displayed a decrease in PPV with volume expansion ( R and NR, $P=0.0001)$, though the decrease in PPV was greater in $\mathrm{R}(P=0.0001)$.

ROC curves were constructed to establish the sensitivity and specificity of CVP, PPV and IJV distensibility in predicting fluid responsiveness. No value of CVP discriminated between $\mathrm{R}$ and NR with good sensitivity and specificity (area under the curve (AUC) 0,68. CI 0,45, 0,75 ) (see Additional file 1). A $>18 \%$ IJV distensibility predicted a $\Delta C I \geq 15 \%$ with a sensitivity of $80 \%$ and a specificity of $95 \%$, AUC 0.915 (CI 0.801 to 0.975 ) (Figure 4). A value $>12.5 \%$ of PPV was able to identify $\mathrm{R}$ with a sensitivity of $96 \%$ and a specificity of $55 \%$, AUC 0.852 (CI 0.723 to 0.936 ) (see Additional file 2). We found no differences between IJV distensibility and PPV ROC curves (Figure 5). Interestingly, the combination of IJV distensibility $>9.9 \%$ and PPV $>12 \%$ predicted fluid responsiveness with a sensitivity of $100 \%$ and specificity of $95 \%$ (see Additional file 3).

\section{Discussion}

The main finding of this study is that US assessment of IJV distensibility during positive-pressure ventilation can discriminate $R$ from NR in critically ill septic patients. Furthermore, the combination of both IJV distensibility and PPV markedly increased the reliability of these predictive indices.

The use of respiratory variations of arterial pressure and aortic flow are accepted bedside parameters of fluid responsiveness and are incorporated into the display screens of many monitoring devices and used to drive resuscitation algorithms [14]. Static parameters, such as CVP, are poor predictors of fluid responsiveness as previously reported [15] and as shown in our study.

Although each dynamic measure may independently predict fluid responsiveness, combining several independently affected physiological parameters, like PPV

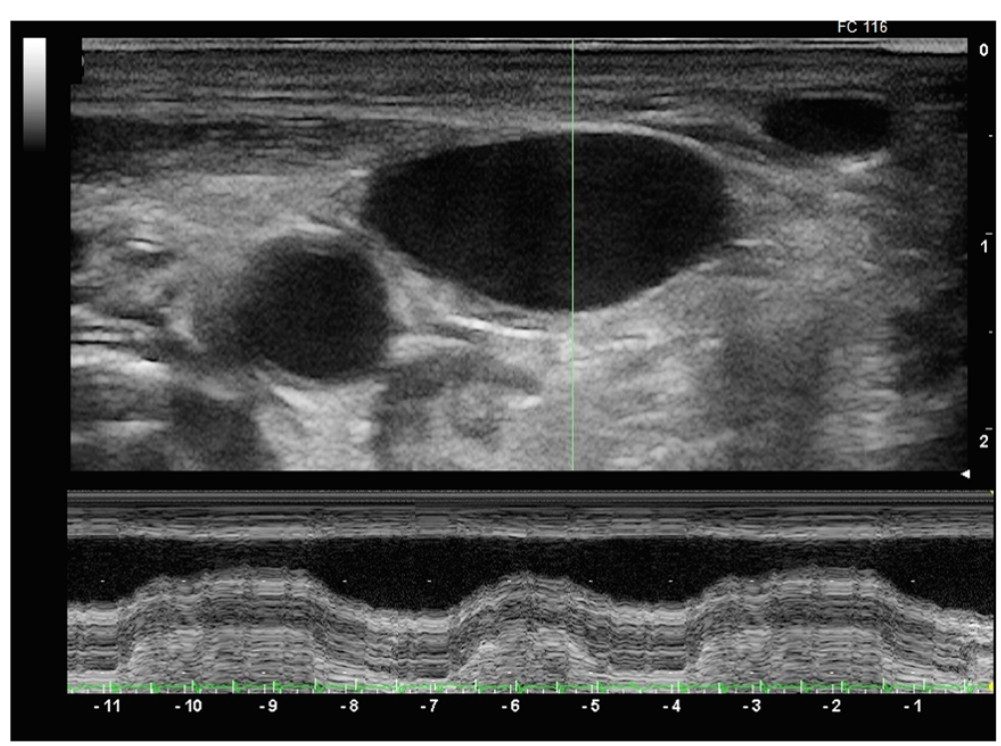

Figure $2 \mathrm{M}$-mode assessment of antero-posterior diameter of the internal jugular vein (IJV) in a responsive patient under mechanical ventilation. A high variability of IJV internal diameter is seen. 


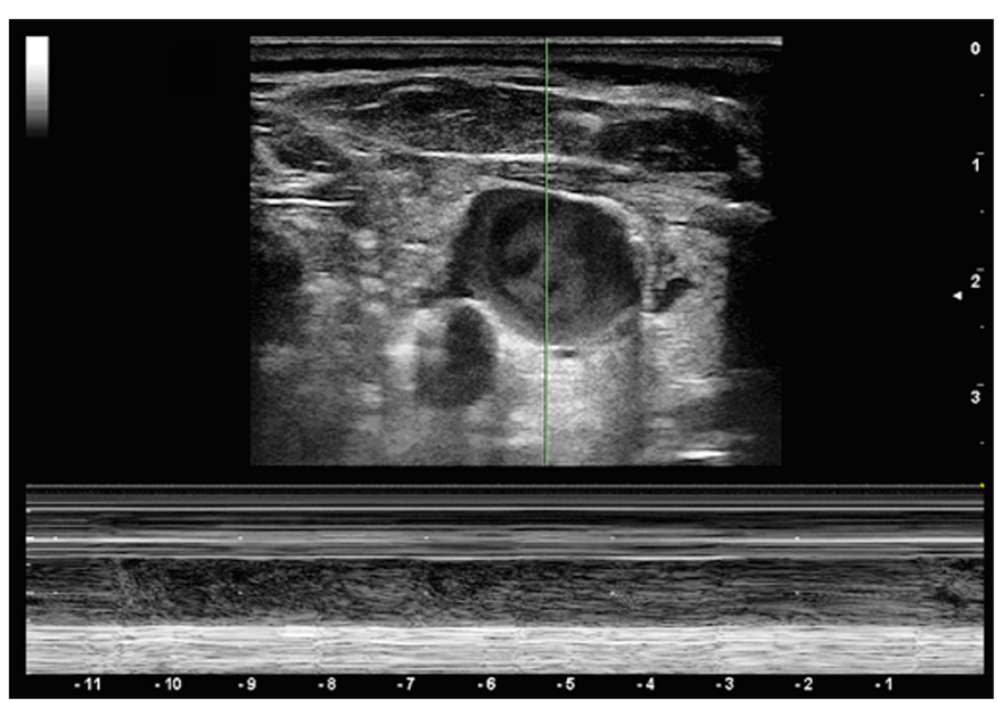

Figure $3 \mathbf{M}$-mode assessment of antero-posterior diameter of the internal jugular vein (IJV) in a non-responsive patient under mechanical ventilation. Lack of variation of IJV diameter is seen.

and IJV distensibility, improves the sensitivity and specificity of these parameters to predict volume responsiveness. The improved performance of the combined measure is due, most likely, to the ability to assess both right and left sided volume responsiveness. IJV distensibility assesses venous return and right ventricular reserve while PPV assesses left ventricular response, both of which are central to controlling overall cardiovascular homeostasis.

Most of the studies evaluating the ability of functional parameters to predict the CI response to volume challenge use ROC-curve analysis to define the optimal threshold, allowing for maximum sensitivity and specificity. Recently

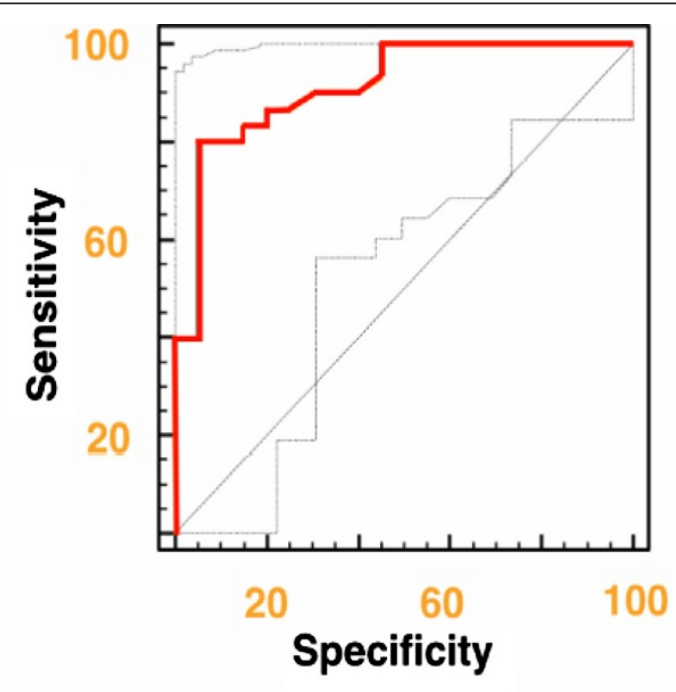

Best Criterion values and coordinates of the ROC curve for IJV distensibility

\begin{tabular}{|l|r|r|r|r|}
\hline Criterion & Sensitivity & $95 \% \mathrm{Cl}$ & Specificity & $95 \% \mathrm{Cl}$ \\
\hline$>9,9$ & 100,00 & $88,4-100,0$ & 55,00 & $31,5-76,9$ \\
\hline$>12,3$ & 90,00 & $73,5-97,9$ & 60,00 & $36,1-80,9$ \\
\hline$>15$ & 83,33 & $65,3-94,4$ & 80,00 & $96,3-94,3$ \\
\hline$>18$ & 80,00 & $61,4-92,3$ & 95,00 & $75,1-99,9$ \\
\hline$>25,5$ & 40,00 & $22,7-59,4$ & 100,00 & $83,2-100,0$ \\
\hline
\end{tabular}

Figure 4 Receiver operator characteristic (ROC) curve of internal jugular vein (IJV) distensibility before fluid administration to predict fluid responsiveness. The gray lines represent $95 \%$ confidence bounds. 


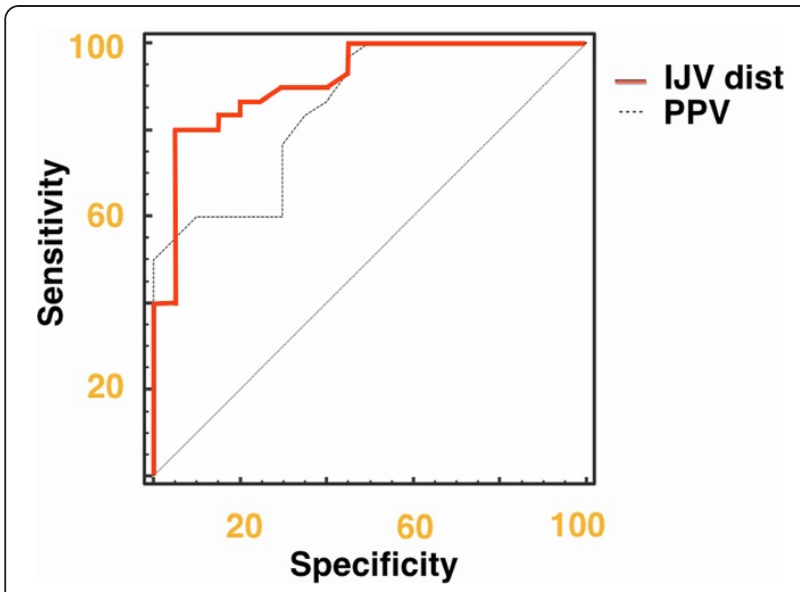

Figure 5 Pairwise comparison of internal jugular vein (IJV) distensibility and pulse pressure variation (PPV) receiver operator characteristic (ROC) curves before fluid administration.

Cannesson et al. used a gray-zone approach evidencing that when PPV decreases into a gray zone between 9 and $13 \%$, uncertainty exists and clinicians should attempt to define volume responsiveness using additional measures [16]. By combining IJV distensibility with PPV, we demonstrate that such gray-zone conditions can be minimized.

Our new measure of IJV diameter change is easily seen with US with minimal training, as this approach is frequently used for US-guided central vein catheterization. We demonstrated the reliability of IJV distensibility on detecting fluid responsiveness of ventilated patients with a value of $16.4 \%$ IJV distensibility having a sensitivity of $80 \%$ and a specificity of $85 \%$ in mechanically ventilated septic patients. Similarly, PPV threshold values of $12.5 \%$ have been reported in the literature to discriminate between $\mathrm{R}$ and NR with similar sensitivity and specificity. Thus, both PPV and IJV distensibility can be used to assess fluid responsiveness. Perhaps more interesting, the combination of both PPV and IJV distensibility improves the sensitivity and specificity of fluid responsiveness prediction with best results for values of IJV $>9.9 \%$ and PPV of $>12 \%$. These data suggest that combining right- and left-sided dynamic parameters should improve their predictive values.

Our study has several limitations. First, all subjects were on mechanical ventilation and fully adapted to the ventilator. However, IVC collapse analysis remains predictive of fluid responsiveness in spontaneously breathing subjects, suggesting that the IJV distensibility index may remain valid as well. Still, the IJV distensibility index needs to be studied in spontaneously breathing subjects. Second, we did not also measure IVC collapse or stroke-volume variation, both measures of volume responsiveness similar in quality to our IJV distensibility and PPV measures, respectively. Still, PPV should be an acceptable surrogate for stroke-volume variation in this type of comparison. Third, changes in CVP influence the IJV pressure and diameter and may decrease relative distensibility. Conditions associated with increased intraabdominal or intrathoracic pressure may potentially increase CVP and can lead to a reduced IJV distensibility index independent of preload responsiveness. We did not study the effect of high CVP on IJV distensibility. However, this process would have similar effects on both SVC and IVC collapse parameters. Accordingly, rightsided US indices, using large-vein collapsibility to predict volume responsiveness, require careful awareness of these potential limitations. Again, these specific clinical conditions may also minimize the predictive values of PPV as well. Fourth, patients' position can influence IJV size. The supine position leads to increased IJV diameter, which is further increased in the Trendelenburg position, whereas sitting or standing can reduce the IJV filling and IJV diameter. Therefore, we made all our measurements from a standard $30^{\circ}$ head of the bed elevated semirecumbent position. However, since this is the recommended position for supine ventilated patients, to minimize aspiration, this limitation needs to be understood and positioning standardized in clinical practice if IJV distensibility index is used for clinical decisionmaking. Fifth, we did not include patients with cardiac disease, who would particularly benefit from functional hemodynamic monitoring. However, in this initial clinical study we did not aim to evaluate the effectiveness of such methods in those patients, because of the potential confounding effect that right heart failure would impose on venous pressures. As cor pulmonale markedly alters other dynamic indices, often making them appear positive when not, we chose to also exclude these patients from our study. However, this patient cohort had a wide range of baseline cardiac reserve, as manifested by having only 30 of 50 patients being volume responsive. Therefore, in this initial validation study, any confounding condition, such as cardiac disease, jugular vein thrombosis or atrial fibrillation was excluded. Sixth, our only cardiovascular challenge was fluid loading. It is not clear if the use of vasoactive drugs, which may independently alter both CVP and the effective circulating blood volume, would independently affect the IJV distensibility index. This interaction and its interpretation remain to be assessed. Finally, as all measurements were performed by a single operator, inter-observer variability in IJV diameter measurement remains to be assessed in future studies.

\section{Conclusions}

Ultrasound evaluation of IJV distensibility is a simple, easy, and readily accessible bedside measure that predicts volume responsiveness in critically ill ventilator-dependent septic patients. Importantly, the combined use of IJV distensibility with PPV increases the predictive value of these 
two volume-responsiveness parameters. Such right- and left-sided dynamic-measure predictor combinations need to be prospectively studied in future clinical trials.

\section{Key messages}

- Internal jugular vein distensibility is a reliable index of fluid responsiveness in mechanically ventilated septic patients and is not inferior to pulse pressure variation

- The combined use of Internal Jugular Vein and PPV could enhance the ability to discriminate fluid responsiveness during mechanical ventilation

\section{Consent}

Written informed consent was obtained from the patient in Figure 1 for publication of the image. A copy of the written consent is available for review by the editor-inChief of this journal.

\section{Additional files}

Additional file 1: Area under the receiver operator characteristic (ROC)
curve for central venous pressure (CVP) and pairwise comparison of
ROC curves of internal jugular vein (IJV) distensibility versus CVP.
Additional file 2: Best criterion values and coordinates of the
receiver operator characteristic (ROC) curve for pulse pressure (PP).
Additional file 3: Best values of sensitivity and specificity
determined by the combination of internal jugular vein
distensibility and pulse-pressure variation in predicting fluid
responsiveness.

\section{Abbreviations}

Cl: cardiac index; CVP: central venous pressure; IJV: internal jugular vein; IVC: inferior vena cava; MAP: mean arterial pressure; MMV: mandatory minute ventilation; NR: non-responders; $\mathrm{PCO}_{2}$ : carbon dioxide partial pressure; PP: pulse pressure; PPV: pulse pressure variation; R: responders; ROC: receiver operator characteristics; $\mathrm{SaO}_{2}$ : arterial oxygen saturation; $\mathrm{SVC}$ : superior vena cava.

\section{Competing interests}

The authors declare that they have no competing interests.

\section{Authors' contributions}

FG has made substantial contributions to conception and design of the study, and interpretation of data; has been involved in drafting the manuscript and revising it critically for important intellectual content; has given final approval of the version to be published; and agrees to be accountable for all aspects of the work in ensuring that questions related to the accuracy or integrity of any part of the work are appropriately investigated and resolved. FB have made substantial contributions to conception and design of the study, acquisition and analysis of data; has been involved in drafting the manuscript; has given final approval of the version to be published, and agrees to be accountable for all aspects of the work in ensuring that questions related to the accuracy or integrity of any part of the work are appropriately investigated and resolved. FF has made substantial contributions to acquisition and interpretation of data; has been involved in drafting the manuscript; has given final approval of the version to be published, and agrees to be accountable for all aspects of the work in ensuring that questions related to the accuracy or integrity of any part of the work are appropriately investigated and resolved. PB has made substantial contributions to acquisition and interpretation of data; has been involved in drafting the manuscript; has given final approval of the version to be published, and agrees to be accountable for all aspects of the work in ensuring that questions related to the accuracy or integrity of any part of the work are appropriately investigated and resolved. ML has made substantial contributions to acquisition of data; has been involved in drafting the manuscript; has given final approval of the version to be published, and agrees to be accountable for all aspects of the work in ensuring that questions related to the accuracy or integrity of any part of the work are appropriately investigated and resolved. MRP has made substantial contributions to analysis and interpretation of data; has been involved in revising the manuscript critically for important intellectual content; has given final approval of the version to be published; and agrees to be accountable for all aspects of the work in ensuring that questions related to the accuracy or integrity of any part of the work are appropriately investigated and resolved. All authors read and approved the manuscript.

\section{Author details}

'Department of Anesthesia and Critical Care Medicine, Cardiothoracic Anesthesia and Intensive Care Medicine, Azienda Ospedaliero Universitaria Pisana, Via Paradisa, 256123 Pisa, Italy. ${ }^{2}$ Department of Anesthesia and Critical Care Medicine, Anestesia e Rianimazione Universitaria IV, Azienda Ospedaliero Universitaria Pisana, Via Paradisa, 256123 Pisa, Italy. ${ }^{3}$ Department of Critical Care Medicine, University of Pittsburgh Medical Center, Pittsburgh, PA, USA.

Received: 27 March 2014 Accepted: 6 November 2014

Published online: 05 December 2014

\section{References}

1. Katz AM: Earnest Henry Starling, his processors, and the "Law of the Heart". Circulation 2002, 106:2986-2992.

2. Preisman $\mathrm{S}$, Kogan $\mathrm{S}$, Berkenstadt H, Perel A: Predicting fluid responsiveness in patients undergoing cardiac surgery; functional hemodynamic parameters including the Respiratory Systolic Variation Test and static preload indicators. Br J Anaesth 2005, 95:746-755.

3. Osman D, Ridel C, Ray P, Monnet X, Anguel N, Richard C, Teboul JL: Cardiac filling pressures are not appropriate to predict hemodynamic response to volume challenge. Crit Care Med 2007, 35:64-68.

4. Michard F, Boussat S, Chemla D, Anguel N, Mercat A, Lecarpentier Y, Richard C, Pinsky MR, Teboul JL: Relation between respiratory changes in arterial pulse pressure and fluid responsiveness in septic patients with acute circulatory failure. Am J Respir Crit Care Med 2000, 162:134-138.

5. Barbier C, Loubieres Y, Schmidt C, Hayon J, Ricome JL, Jordin F, VeillardBaron A: Respiratory changes in inferior vena cava diameter are helpful in predicting fluid responsiveness in ventilated septic patients. Intensive Care Med 2004, 30:1740-1746.

6. Veillard-Baron A, Chergni K, Rabiller A, Peyrouset O, Page B, Beanchet A, Jordin F: Superior vena cava collapsibility as a change of volume status in ventilated septic patients. Intensive Care Med 2004, 30:1734-1739.

7. Constant J: Using internal jugular pulsations as a manometer for right atrial pressure measurements. Cardiology 2000, 93:26-30.

8. Sankoff J, Zidulka A: Non-invasive method for the rapid assessment of central venous pressure: description and validation by a single examiner. West J Emerg Med 2008, 9:201-205.

9. Conn RD, O'Keefe JH: Simplified evaluation of the jugular venous pressure: significance of inspiratory collapse of jugular veins. Mo Med 2012, 109:150-152.

10. Chua Chiaco JM, Parikh NI, Fergusson DJ: The jugular venous pressure revisited. Cleve Clin J Med 2013, 80:638-644.

11. Dellinger RP, Levy MM, Rhodes A, Annane D, Gerlach H, Opal SM, Sevransky JE, Sprung CL, Douglas IS, Jaeschke R, Osborn TM, Nunnally ME, Townsend SR, Reinhart K, Kleinpell RM, Angus DC, Deutschman CS, Machado FR, Rubenfeld GD, Webb S, Beale RJ, Vincent JL, Moreno R: Surviving Sepsis Campaign Guidelines Committee including The Pediatric Subgroup. Surviving Sepsis Campaign: international guidelines for management of severe sepsis and septic shock, 2012. Intensive Care Med 2013, 39:165-228.

12. Donati A, Carsetti A, Tondi S, Scorcella C, Domizi R, Damiani E, Gabbanelli V, Münch C, Adrario E, Pelaia P, Cecconi M: Thermodilution vs pressure recording analytical method in hemodynamic stabilized patients. J Crit Care 2014, 29:260-264.

13. Prekker ME, Scott NL, Hart D, Sprenkle MD, Leatherman JW: Point-of-care ultrasound to estimate central venous pressure: a comparison of three techniques. Crit Care Med 2013, 41:833-841. 
14. Pinsky MR, Payen D: Functional hemodynamic monitoring. Crit Care 2005, 9:566-572.

15. Marik PE, Baram M, Vahid B: Does central venous pressure predict fluid responsiveness? A systematic review of the literature and the tale of seven mares. Chest 2008, 134:172-178.

16. Cannesson M, Le Manach Y, Hofer CK, Goarin JP, Lehot JJ, Vallet B, Tavernier $B$ : Assessing the diagnostic accuracy of pulse pressure variations for the prediction of fluid responsiveness: a "gray zone" approach.

Anesthesiology 2011, 115:231-241.

Submit your next manuscript to BioMed Central and take full advantage of:

- Convenient online submission

- Thorough peer review

- No space constraints or color figure charges

- Immediate publication on acceptance

- Inclusion in PubMed, CAS, Scopus and Google Scholar

- Research which is freely available for redistribution 